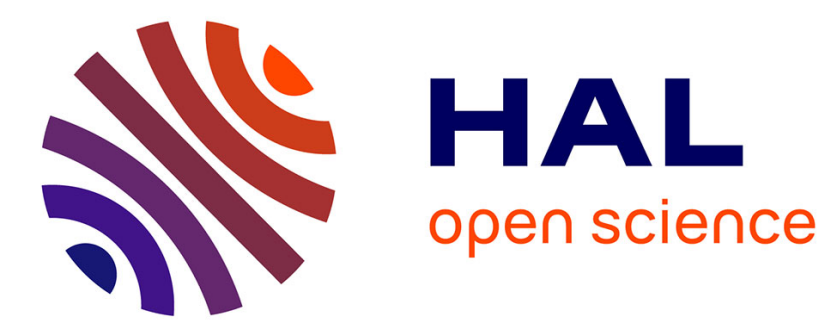

\title{
Reactivity of Ni-Al nanocomposites prepared by mechanical activation: a molecular dynamics study
}

A. Fourmont, S. Le Gallet, O. Politano, C. Desgranges, Florence Baras

\section{To cite this version:}

A. Fourmont, S. Le Gallet, O. Politano, C. Desgranges, Florence Baras. Reactivity of Ni-Al nanocomposites prepared by mechanical activation: a molecular dynamics study. Journal of Applied Physics, 2021, 129 (6), pp.065301. 10.1063/5.0037397 . hal-03347322

\section{HAL Id: hal-03347322 \\ https://hal.science/hal-03347322}

Submitted on 17 Sep 2021

HAL is a multi-disciplinary open access archive for the deposit and dissemination of scientific research documents, whether they are published or not. The documents may come from teaching and research institutions in France or abroad, or from public or private research centers.
L'archive ouverte pluridisciplinaire HAL, est destinée au dépôt et à la diffusion de documents scientifiques de niveau recherche, publiés ou non, émanant des établissements d'enseignement et de recherche français ou étrangers, des laboratoires publics ou privés. 
Reactivity of $\mathrm{Ni}-\mathrm{Al}$ nanocomposites prepared by mechanical activation: a molecular dynamics study

\author{
A. Fourmont, ${ }^{1, \text { a) }}$ O. Politano, ${ }^{1, b)}$ S. Le Gallet, ${ }^{1, \text { c) }}$ C. Desgranges, ${ }^{2, d)}$ and F. \\ Baras $^{1,}$ e) \\ 1) Laboratoire Interdisciplinaire Carnot de Bourgogne, \\ UMR 6303 CNRS-Université Bourgogne Franche-Comté, \\ 9 Avenue A. Savary, BP 47 870, F-21078 DIJON Cedex, \\ FRANCE \\ ${ }^{2)}$ Safran Tech, Materials and Processes Department, Magny-les-Hameaux,
}

France

(Dated: 12 January 2021)

High energy ball milling of metallic powders leads to high reactivity in the milled mixture. The reaction is often faster and starts at a lower temperature. However, the mechanisms responsible for this high reactivity are not yet completely understood. The aim of this study is to evaluate one of the possible activating factors of this heightened reactivity: nano-scale mixing of the reagents. Molecular Dynamics was used to analyze the role of an amorphous Ni-Al mixing layer, mimicking the powder microstructure after milling, between two $\mathrm{Ni}$ layers. The impact of temperature and stoichiometry was investigated in relation to the formation of the $B 2-\mathrm{NiAl}$ intermetallic compound. At low temperatures, pre-mixing does not seem to slow down the diffusion of $\mathrm{Ni}$ atoms in an amorphous Al region. Homogeneous nucleation was observed in this peculiar milled microstructure. These two phenomena explain why the nano-scale mixing observed experimentally after high energy milling is indeed an activating factor in the reactivity of metallic systems such as $\mathrm{Ni}-\mathrm{Al}$.

\footnotetext{
${ }^{a)}$ Electronic mail: Adrien.Fourmont@u-bourgogne.fr

b)Electronic mail: Olivier.Politano@u-bourgogne.fr
} 
${ }^{c}$ Electronic mail: sophie.le-gallet@u-bourgogne.fr

d) Electronic mail: clara.desgranges@safrangroup.com

e)Electronic mail: Florence.Baras@u-bourgogne.fr 


\section{INTRODUCTION}

Milling several compounds in order to mix them is a very old and common technique. However, high energy milling is relatively new to the domain of metallurgy ${ }^{1}$. Despite its widespread use today, the high energy ball milling of metallic powders is not completely understood, especially in terms of the evolution of the microstructure at atomic scale during the milling or even the description of ball movement ${ }^{2}$. In the area of Self-Propagating High Temperature Synthesis (SHS), high energy ball milling is a well-known elaboration process. First, two compounds are milled together and then the milled powders are heated at a low temperature (up to $900 \mathrm{~K}$ ). When the ignition temperature is reached, the reaction starts and self-propagates. It has been observed that milling two powders leads to high reactivity and solid-state reactions, which translate into a lower ignition temperature and a faster reaction ${ }^{3-5}$. In this situation, the amount of the liquid phase is reduced, and the reaction occurs at a moderate temperature as compared to other SHS processes such as SHS in nanolaminates. One of the more widely studied systems is the $\mathrm{Ni}-\mathrm{Al}$ system which forms the intermetallic $\mathrm{Ni}_{50} \mathrm{Al}_{50}$ compound with an ordered $B 2$ structure. To explain this high reactivity, Rogachev et al. studied milled powders of $\mathrm{Ni}+\mathrm{Al}$ by means of High-Resolution Transmission Electron Microscopy (HRTEM) and suggested 6 activating factors ${ }^{6}$ :

(i) decreasing apparent activation energy by the magnitude of the energy stored in reactants during MA;

(ii) increasing atomic mobility due to high concentration of the grain boundaries and defects created by plastic deformation;

(iii) formation of non-equilibrium meta-stable phases;

(iv) increase in the contact (interfacial) surface area between reactants;

(v) formation of freshly formed reactive surfaces; and 
(vi) nano-scale mixing of the reagents.

These factors are nearly impossible to thoroughly study experimentally because of the time and space scales. Despite the recent success of innovative experiments investigating milling regimes in planetary ball mills ${ }^{7}$, today's technologies do not make in-situ microscopic observations possible. Thus, microscopic simulations such as Molecular Dynamics (MD) could provide a useful tool to describe both milling and SHS processes. The milling mechanism has been modelized in several ways in the literature. The sliding of metallic blocks and the subsequent friction leading to mixing has been studied by several research groups ${ }^{8-10}$. They have observed mixing at the atomic scale in an amorphous zone and have noted that the mixing resulted from ballistic diffusion rather than classic thermal diffusion. These teams also observed the formation of structural defects resulting from this friction. Chen et al. studied the sliding of blocks of $\mathrm{Ni}$ and $\mathrm{Al}$. They have reported that the mixing layer is mainly formed in the softer $\mathrm{Al}$ material $^{11,12}$. Odunuga et al. and Delogu et al. evaluated another kind of simulation using cyclic deformations that mimic milling ${ }^{13,14}$. They studied forced chemical mixing driven by plastic deformation and observed that the mixing resulted from dislocation gliding and that it was similar to the mixing of a substance subject to a turbulent flow. The reactivity of these simulated systems is to analyze because two main, interdependent aspects have to be considered: the creation of structural defects and the induced chemical mixing. Adding to the complexity of analysis is the fact that the importance of one aspect could overtake that of the other due to issues of scale.

Microscopic simulation of the reactivity of a milled system is a challenging undertaking because of the co-occurrence of many factors. Preliminary attempts to examine the reactivity of activated systems have been carried out in specific cases.

Cherukara et al., Manukyan et al. and Xiong et al. studied the shock between powder particles and the subsequent reactivity ${ }^{15-18}$. Here, the rise in temperature is a consequence of the impact, contrary to the case of a classic SHS process. This is a one step process: shock-induced chemistry. The authors demonstrated that in this case, compres- 
sion is associated with the sharp rise in temperature and that the subsequent reaction is dominated by interdiffusion. They also showed that porosities play a major role by acting as hot spots during the deformation ${ }^{17}$. Witbeck et al. have evaluated the effects of lattice defects and grain boundaries ${ }^{19,20}$. This work corresponds to an exploration of activating factor (ii). The authors observed that point defects greatly increased the reaction speed in SHS propagation, whereas grain boundaries acted as heterogeneous nucleation sites in the formation of the intermetallic compound $B 2-\mathrm{NiAl}$ which further inhibited $\mathrm{Ni}$ diffusion. This study was performed in the context of nanolaminates where temperature increased tremendously (up to $2200 \mathrm{~K}$ ); indeed, temperature is the key factor in the reaction. However, these findings are not necessarily relevant to the case of milled systems, in which temperature and the resulting diffusion are not likely to be the main factors. Crone et al. and Cherukara et al. have indirectly studied activating factors (iv) and (v): the effect of surfaces ${ }^{21,22}$. They have reported that the misfit strain decreased the activation energy of the reaction. They also observed that voids and porosity led to a slower mechanism compared to the case in which the two elements were in direct contact. The Weihs group has indirectly studied (vi) in the case of temperature driven mixing ${ }^{23-25}$. They noted that a pre-mixing step hindered diffusion and that a nano-scale gradient suppressed the homogeneous nucleation of B2-NiAl. They also observed that $B 2-\mathrm{NiAl}$ readily nucleates and grows at the interface between an amorphous pre-mixed region and an $f c c-\mathrm{Ni}$ block. Kuhn et al. and Ovrutsky et al. have studied nucleation in an $\mathrm{Ni}_{50} \mathrm{Al}_{50}$ undercooled amorphous zone ${ }^{26,27}$. They analyzed the crystallization resulting from decreasing temperature. They observed that nucleation occurred in two steps: segregation of the $\mathrm{Ni}$ and $\mathrm{Al}$ into an amorphous but ordered structure, and, then, crystallization into the $B 2$ compound. They observed that $B 2-\mathrm{NiAl}$ homogeneous nucleation began at $900 \mathrm{~K}$. Examining the case of a bilayer configuration, Baras et al. have reported that the crystallization of $B 2-\mathrm{NiAl}$ resulted from a liquid phase ${ }^{28,29}$.

A systematic study of the effect of mixing (vi) in the framework of milled systems is still lacking. Indeed, two main parameters significantly differ from those which apply 
to studies on laminate systems: first, the temperature range is significantly lower and secondly, the reaction mainly occurs in solid-state. In addition, the microstructure of such systems includes more defects in the form of large amorphous zones generated during the milling process. It is nearly impossible to take into account all the significant parameters to model a real-world milled Ni/Al reactive materials at once. In the present work, we focused on the effect of pre-mixing in an amorphous system and on the resulting crystallization of $\mathrm{B} 2 \mathrm{-NiAl}$ at low temperatures (below the melting temperature of Al). Indeed, a careful examination on the current literature on the topic led us to believe that this viewing angle was of primary importance ${ }^{30}$. This study modelized a two-step process in which the reactants are first milled and then heated, as is usually the case in such experiments.

\section{SIMULATION DETAILS}

To describe the Ni-Al system, we employed the classic Molecular Dynamics (MD) approach using the Embedded-Atom Method (EAM) potential developed by Purja Pun and Mishin ${ }^{31}$. This interatomic potential has been fitted to reproduce a large set of physical quantities determined experimentally or by ab-initio calculations. It therefore accurately describes the main physical properties of the pure elements (i.e. $\mathrm{Ni}$ and $\mathrm{Al}$ ) as well as selected intermetallic compounds, namely $B 2-\mathrm{NiAl}$ and $L 1_{2}-\mathrm{Ni}_{3} \mathrm{Al}$. Despite its good transferability, this potential necessarily deals with a simplified system containing a limited number of phases as compared to a real $\mathrm{Ni}-\mathrm{Al}$ system. Table I reports the melting temperature, cohesive energies and lattice parameters computed using this potential ${ }^{32}$. The MD simulations were conducted using the Large-scale Atomic/Molecular Massively Parallel Simulator (LAMMPS) open-source software ${ }^{33}$ and the atomic visualizations were effected via the Open Visualization Tool (OVITO) $)^{34}$.

Following on from our previous work ${ }^{28}$, we considered a layered Ni-Al-Ni system with the following characteristics. The reference system is made up of one layer of $\mathrm{Al}$ of 
TABLE I. Physical properties of pure elements and intermetallics calculated using Purja Pun and $\operatorname{Mishin}^{31}$. For more details see Turlo et $a l .{ }^{32}$.

\begin{tabular}{l|c|l|l|l}
\hline \hline Phase & \multicolumn{2}{|c|}{ Thermodyamic properties } & \multicolumn{2}{c}{ Structural properties } \\
\hline & $T_{m}(\mathrm{~K})$ & $T_{m}$ exp. (K) & Cohesive energy (eV) & Lattice parameter (nm) \\
\hline $\mathrm{Ni}$ & 1710 & 1728 & -4.45 & 0.352 \\
$\mathrm{Al}$ & 1055 & 933 & -3.36 & 0.405 \\
$B 2-\mathrm{NiAl}$ & 1675 & 1850 & -4.51 & 0.283 \\
$L 1_{2}-\mathrm{Ni}_{3} \mathrm{Al}$ & 1755 & 1720 & -4.63 & 0.353 \\
\hline \hline
\end{tabular}

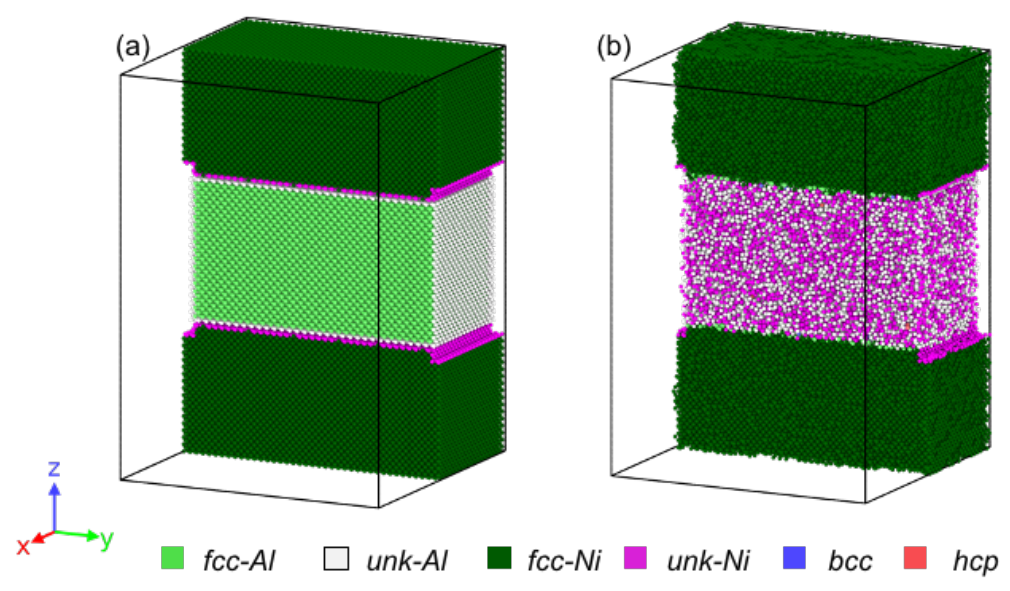

FIG. 1. Geometry of the system. (a) Reference system (b) Mixing layer. Dark green $=f c c-\mathrm{Ni}$, light green $=f c c-\mathrm{Al}$, pink $=u n k-\mathrm{Ni}$, white $=u n k-\mathrm{Al}$ where $u n k$ stands for unknown atoms. (For the interpretation of the references to color in this figure, the reader is referred to the website where this article appears.)

35 atomic planes in between two Ni layers of 36 atomic planes each along the $z$-direction (Fig. 1a). Both pure metals are in $f c c$ configuration and the interface orientation is (001). The typical size of the simulation box is $L_{x}=L_{y} \sim 14 \mathrm{~nm}$ and $L_{z}=20 \mathrm{~nm}$. The system is submitted to periodic boundary conditions in all directions. The initial distance $\delta$ between the Ni- and Al-atomic planes at the interface is $2.5 \AA$. The system 
is made up of 305214 atoms $(\mathrm{n}(\mathrm{Ni})=231276$ and $\mathrm{n}(\mathrm{Al})=73$ 938). The inner layer is defined as the layer of Al plus 3 atomic planes of Ni interfaces on each side. The width in the $x$ and $y$ directions of the inner layer is chosen to be smaller than that of the outer Ni layers $\left(L_{x}\right.$ (inner) $<L x$ (outer) and $L_{y}$ (inner $)<L_{y}$ (outer $\left.)\right)$. The thickness of the inner layer is $8.3 \mathrm{~nm}$. This specific geometry including a narrower inner layer allows us to avoid artificial constraints due to the application of periodicity on both inner and outer layers during the construction of the system and its subsequent evolution. Each system is then denoted as 'REF $x x \mathrm{~K}$ ' where $x x \mathrm{~K}$ refers to the temperature of the simulation (see Table II).

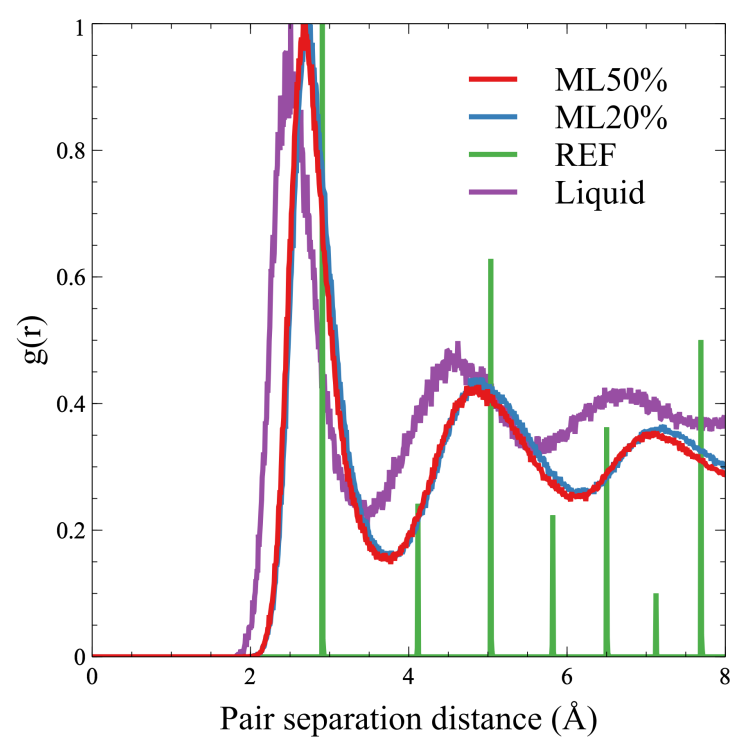

FIG. 2. Pair correlation function $g(r)$ of the initial configurations after the procedure, normalized on the first peak. $g(r)$ in the case of pure liquid $\mathrm{Ni}+\mathrm{Al}$ has been added for the sake of information. (For interpretation of the references to color in this figure, the reader is referred to the website where this article appears.)

After high energy ball milling of $\mathrm{Ni}-\mathrm{Al}$ powders, one can observe around the remaining Ni grains (the toughest element) a mixed layer composed of highly crushed Al with a certain quantity of $\mathrm{Ni}$. 
In order to mimic this mixing layer resulting from mechanical activation, a microstructure consisting of an amorphous layer placed in between two Ni layers was designed. The $f c c-\mathrm{Ni} / f c c-\mathrm{Al} / f c c-\mathrm{Ni}$ system was heated to above the melting temperature of $\mathrm{Al}$ and $\mathrm{Ni}(2000 \mathrm{~K})$ in the isothermal-isobaric ensemble (NPT) over a very short time, namely $10 \mathrm{ps}$. This heating step resulted in the complete melting of the Al layer but an incomplete melting of the $\mathrm{Ni}$. The sample was then cooled to room temperature $(300 \mathrm{~K})$ over $10 \mathrm{ps}$. The inner Al layer became amorphous while the outer layer remained crystallized at the end of this rapid heating-cooling treatment. The mixing layer is defined as a layer of $7.8 \mathrm{~nm}$ in thickness along the $z$-direction in the middle of the system. The mixing layer is just slightly narrower than the inner layer. A random substitution of the atoms in the mixing layer according to their type was then carried out in order to fix the $\mathrm{Ni}$ concentration (ranging from 10 to 60 at.\%). The energy of the system was then minimized by means of a conjugate gradient procedure. The goal of the above procedure was to create a representative model microstructure acting as a starting configuration for the reactivity simulation. It does not reflect any sequence of physical phenomena and only the resulting bilayer configuration with a pre-mixed zone is of interest. Each system is denoted 'MLXX\% $x x \mathrm{~K}$ ' where the mixing layer consists of $\mathrm{XX}$ at. $\%$ of $\mathrm{Ni}$ and $x x \mathrm{~K}$ is the temperature of the simulation (see Table II). The system contains 305013 atoms with $n(\mathrm{ML})=85220$ in the mixing layer. For example, the mixing layer in the ML20\% system contains $17036 \mathrm{Ni}$ atoms. In order to ensure that most of the mixing layer was truly amorphous at $300 \mathrm{~K}$, we chose to consider the pair correlation function $g(r)$ of the mixing layer as our main criterion. The $g(r)$ functions of the inner layers of our different systems are displayed in Fig. 2. The pair correlation function of the mixing layer created in this way is similar to that of a liq-Al system (i.e. melted $\mathrm{Al}$ ) generated by heating $f c c-\mathrm{Al}$ at $2000 \mathrm{~K}$ over a long period: $3 \mathrm{~ns}$. Hence, the amorphous character of the mixing layer is indeed mimicked by means of this rapid heating-cooling treatment. Note that the substitution ratio does not modify the degree of amorphisation. The configuration of the initial system with a mixing layer is depicted 
TABLE II. Set of simulated systems.

\begin{tabular}{lccl}
\hline \hline Generic name & Ni at ${ }^{\text {a }}$ & Temperature (K) & Name \\
\hline REF (reference system) & $0 \%$ & $600 \mathrm{~K}$ & REF600K \\
& & $800 \mathrm{~K}$ & REF800K \\
& & $900 \mathrm{~K}$ & REF900K \\
& & $1200 \mathrm{~K}$ & REF1200K \\
\hline \hline ML (mixing layer) & $20 \%$ & $900 \mathrm{~K}$ & ML20\%900K \\
\hline ML (mixing layer) & $20 \%$ & $1200 \mathrm{~K}$ & ML20\%1200K \\
\hline ML (mixing layer) & $30 \%$ & $900 \mathrm{~K}$ & ML30\%900K \\
& $30 \%$ & $1200 \mathrm{~K}$ & ML30\%1200K \\
\hline ML (mixing layer) & $40 \%$ & $900 \mathrm{~K}$ & ML40\%900K \\
& $40 \%$ & $1200 \mathrm{~K}$ & ML40\%1200K \\
\hline \hline ML (mixing layer) & $50 \%$ & $600 \mathrm{~K}$ & ML50\%600K \\
\hline $50 \%$ & $800 \mathrm{~K}$ & ML50\%800K \\
& $50 \%$ & $900 \mathrm{~K}$ & ML50\%900K \\
\hline
\end{tabular}

a in the mixing layer.

in Fig. 1b. In order to study the reactivity of such systems, both REF and MLXX\% systems were studied at various temperatures in the isothermal-isobaric ensemble (NPT) in the range of $600 \mathrm{~K}-1200 \mathrm{~K}$ around the bulk melting temperature of aluminum.

Several indicators allow us to follow the evolution of the system at the microscopic level. If we calculate the local lattice structure according to the common neighbor analysis, we obtain the local configuration around a given atom. It is possible to distinguish between different configurations: $b c c(1), f c c(2), h c p$, and unknown (0). Each atom is thus labeled by the color of the species and by its local lattice structure. The potential 
energy per atom, which is very sensitive to the local environment of a given atom, was also evaluated. In addition, global indicators were followed during the evolution of the system: the atomic percentage of $\mathrm{Ni}$ atoms in the inner or mixing layer; the amount of $b c c$-atoms in at.\% out of the maximum that could be formed

$$
\Xi=100 \times \frac{n(b c c)}{2 \times n(\mathrm{Al})}
$$

where $n(b c c)$ and $n(\mathrm{Al})$ are the numbers of $B 2$ - and $\mathrm{Al}$-atoms in the mixing layer (B2 atoms form a $b c c$ lattice if we do not make the distinction between atomic species). If all Al-atoms are $b c c, \Xi$ is close to $100 \%$ and the phase is pure B2-NiAl. $\Xi$ makes the comparison between several stoichiometries possible. A cluster analysis was developed in order to analyze the nucleation and growth of the intermetallic phase during evolution of the system. A cluster of atoms is defined as a set of neighboring $b c c$ atoms. If the cluster is made up of at least 20 atoms, the cluster is counted as a nucleus.

\section{RESULTS AND DISCUSSIONS}

In a bilayered system $\mathrm{Ni}-\mathrm{Al}-\mathrm{Ni}$, the typical evolution at an elevated temperature consists of several stages: the melting of aluminum, the progressive dissolution of Ni-atoms into the liquid layer and, eventually, the formation of $B 2-\mathrm{NiAl}$ at interfaces. The corresponding scheme of reaction reads as follows:

$$
\mathrm{Ni}(\mathrm{s})+\mathrm{Al}(\mathrm{l}) \rightarrow \mathrm{Ni}(\mathrm{s})+\mathrm{AlNi}_{x}(\mathrm{l}) \rightarrow \mathrm{Ni}(\mathrm{s})+\mathrm{AlNi}_{x^{\prime}}(\mathrm{l})+\mathrm{NiAl}(\mathrm{s})
$$

This mechanism is named mosaic dissolution-precipitation ${ }^{35}$. After saturation of the Almelt by $\mathrm{Ni}$-atoms, crystallites of the intermetallic products $(\mathrm{NiAl})$ nucleate at the solidliquid interface and grow along this interface. The microstructure consists of rounded $\mathrm{NiAl}$ grains separated by liquid gaps. Further growth of $\mathrm{NiAl}$ crystallites occurs due to diffusion through liquid gaps and precipitation at the intermetallic-liquid interface. Fig. 3 tracks the evolution of amorphous- and $f c c$-atoms in the reference system at $1200 \mathrm{~K}$ (REF1200K), above the melting temperature of Al. The rapid increase in the 


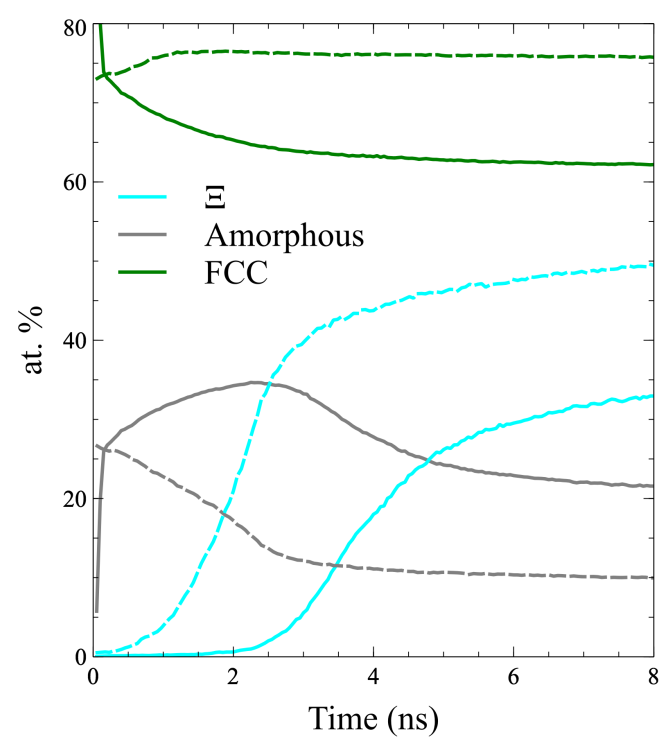

FIG. 3. Evolution of the structure type as a function of time at 1200K. Dashed lines correspond to the ML50\%1200K system and solid lines to the REF1200K system.

number of amorphous atoms and decrease in $f c c$-atoms corresponds to the melting of the inner layer. This melting step occurs in less than $0.2 \mathrm{~ns}$. From 0.2 to $2 \mathrm{~ns}$, the number of $f c c$-atoms slowly decreases while the number of amorphous atoms increases. This corresponds to the progressive dissolution of $\mathrm{Ni}$ into liquid Al. At $2 \mathrm{~ns}$, the number of amorphous atoms reaches a maximum and $\mathrm{B} 2 \mathrm{-NiAl}$ starts to form (formation of $\mathrm{B2}$ $\mathrm{NiAl}$ is followed by $\Xi$ ). A plateau is reached at about $8 \mathrm{~ns}$. More than half of the Al-atoms remain in the liquid state.

Next, we considered a system with a premixed layer that mimics an activated $\mathrm{Ni} / \mathrm{Al}$ system after milling. The mixing layer contains 50 at.\% of $\mathrm{Ni}$ and the bilayer is heated at $1200 \mathrm{~K}$. The behavior of the ML50\% system is actually very different from that of the REF1200K. There is no delay in the formation of $B 2-\mathrm{NiAl}$ and the ratio $\Xi$ reaches a higher value close to $50 \%$. The decrease in $u n k$-atoms (amorphous) is concomitant with the formation of $\mathrm{B2}-\mathrm{NiAl}$. As amorphous $\mathrm{Al}-$ and $\mathrm{Ni}$-atoms are present in the mixing layer from the start, the reorganization of atoms takes place from the very beginning. No prior melting was required. Note that the number of $f c c$-atoms increased slightly 
at the start of the phase transformation before reaching a plateau. We observed that the number of $f c c$-atoms is higher in the ML50\% system as depicted in Fig. 9.

The main differences observed are certainly due to the fact that the melting and dissolution steps have already been performed in ML50\%. However, it has been noted that a mixing layer hinders diffusion ${ }^{23}$. Indeed, according to Fick's Law, the concentration gradient decreases and diffusion slows down. In addition, diffusion of $\mathrm{Ni}$ atoms in a Nickel amorphous zone is known to be faster than in a Nickel crystalline zone, as it was reported by Manukyan et al. for instance ${ }^{36}$; in this case, the use of amorphous $\mathrm{Ni}$ as reactant was proved to be more efficient than crystalline $\mathrm{Ni}$.

In order to evaluate the effect of melting/dissolution as compared to diffusion in B2formation, we studied the diffusion of Ni-atoms in both systems. Figure 4a depicts the evolution of the Ni concentration (at.\%) in the mixing layer and the evolution of the $B 2$ phase in the ML50\% and REF systems. Ni concentrations were calculated in the whole mixing layer (solid lines) and in the $1 \mathrm{~nm}$ slice just above or below the interface (dashed lines) in order to evaluate the dissolution of $\mathrm{Ni}$ coming from the two $f c c-\mathrm{Ni}$ blocks. We also considered the ML20\% system at $1200 \mathrm{~K}$, where the inner layer is not saturated in Ni. The evolution of Ni-concentration can be correlated with the appearance of $B 2$-nuclei as shown in Fig. 4b.

In ML50\%, the Ni concentration does not evolve much since the inner layer is close to saturation in $\mathrm{Ni}^{37}$. There is nevertheless some limited diffusion at the interface. The only phenomenon which occurs is the ordering in $B 2$. Nucleation proceeds very quickly until $0.5 \mathrm{~ns}$ at which point the seeds coalesce. In the end, there is one main grain of 34000 atoms. In a perfect $B 2$ structure, the grain corresponds to a total volume of 410 $\mathrm{nm}^{3}$. Assuming the grain is a sphere, it has a radius of $4.6 \mathrm{~nm}$.

In ML20\%, the Ni concentration in the $1 \mathrm{~nm}$ slice close to the interface undergoes a sharp increase until $0.5 \mathrm{~ns}$, then continues to increase. The Ni concentration in the entire mixing layer increases more slowly and reaches a plateau value of approximately $35 \%$ at $3.5 \mathrm{~ns}$. The inflexion point in the evolution of $\Xi$ in ML20\% corresponds to the plateau 

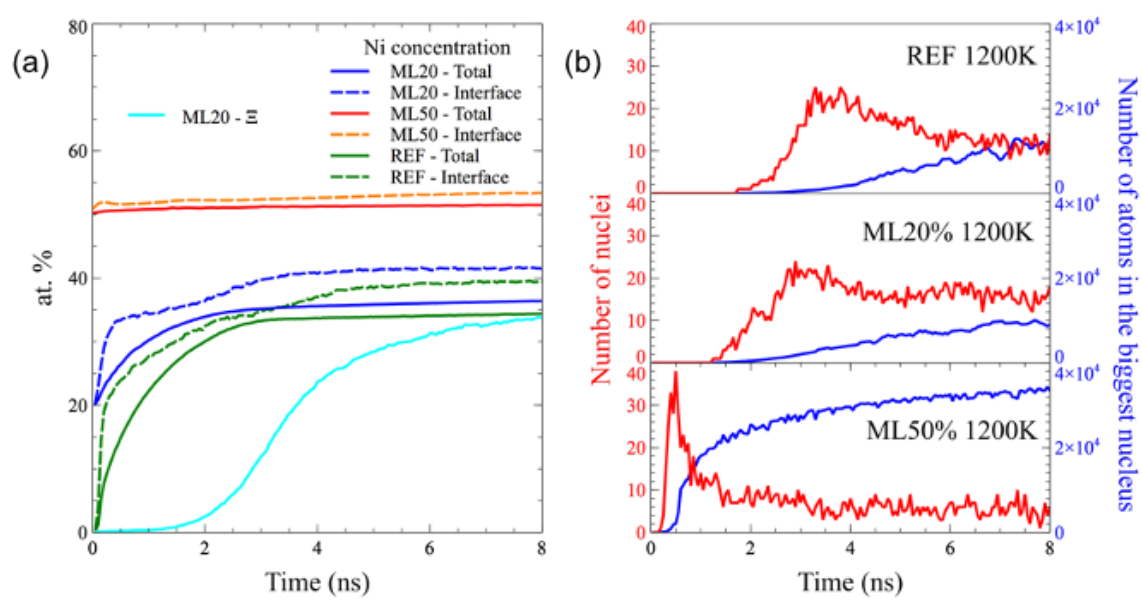

(c)
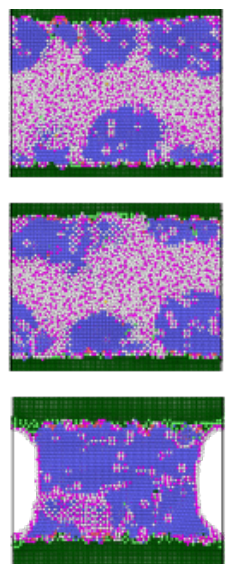

FIG. 4. (a) Evolution of the Ni concentration in the mixing layer (solid lines), Ni concentration in a $1 \mathrm{~nm}$ slice just above or below the interface (dashed lines) and \% of $B 2$ formed $\Xi$ in ML20\%. (b) Evolution of the number of $B 2$ nuclei (red) and the size of the biggest nucleus (number of atoms) (blue) as a function of time. (c) Snapshot of the mixing layer for REF (top), ML20\% (middle) and ML50\% (bottom) at $8 \mathrm{ns.}$

in $\mathrm{Ni}$ concentration. The formation of $\mathrm{B} 2-\mathrm{NiAl}$ seems to begin efficiently when the $\mathrm{Ni}$ concentration in the whole layer reaches a steady value. From 0.5 to $2 \mathrm{~ns}, \mathrm{Ni}$-atoms migrated from interfaces to the 'center' of the mixing layer and $B 2$ seeds appeared. After $1.5 \mathrm{~ns}$, nucleation takes place with an increasing number of nuclei (Fig. 4b). After $3 \mathrm{~ns}$, the number of nuclei decreased but some grains grew towards the 'center' of the mixing layer. At $8 \mathrm{~ns}$, a limited number of rounded grains clung to the interfaces (Fig. 4c). In ML20\%, phase formation proceeds through heterogeneous nucleation: no grains formed spontaneously in the bulk of the mixing layer.

The behavior of the REF sample is similar to that observed in ML20\%, except that the $\mathrm{Ni}$ concentration reaches its steady value slightly later and this value is lower. $\mathrm{Nu}-$ cleation of $B 2-\mathrm{NiAl}$ grains is shifted to $2 \mathrm{~ns}$. In addition, fewer but larger grains are formed (biggest nucleus $r=3.2 \mathrm{~nm}$ ). Small grains merged with larger ones, as there is some coalescence (see Supplementary Materials). 
At high temperature $(1200 \mathrm{~K})$, the REF system and the ML system with a low $\mathrm{Ni}$ concentration exhibit similar behavior: dissolution of Ni close to the interface, heterogeneous nucleation, further dissolution of Ni to the 'center', growth. But in the case of the premixed layer, the formation of $B 2$ occurs sooner and the system is more reactive.

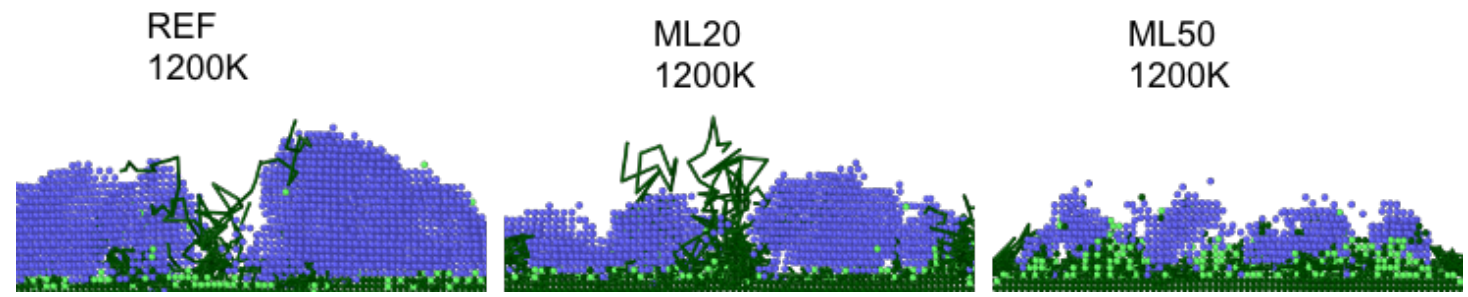

FIG. 5. Snapshots of the atoms at $5 \mathrm{~ns}$ for REF and ML20 and at $0.3 \mathrm{~ns}$ for ML50. The trajectories of some $\mathrm{Ni}$ atoms from the $f c c$ block calculated over the 8 ns simulation are also displayed. Dark green $=f c c-\mathrm{Ni}$, light green $=f c c-\mathrm{Al}$, blue $=b c c$.

Figure. 5 shows the diffusion paths during the $8 \mathrm{~ns}$ simulation of the Ni coming from the $f c c$-block. In the case of the REF and the ML20\% systems, the grain boundaries act as channels to bring $\mathrm{Ni}$ atoms into the middle of the inner layer. As a result, the 50-50 stoichiometry is reached and $B 2-\mathrm{NiAl}$ continues to grow towards the middle. In the case of ML50\%, there is almost no diffusion from the Ni blocks to the middle of the layer, confirming the results presented in Fig. 4a.

We next investigated the influence of $\mathrm{Ni}$ content in the mixing layer on the mechanism of $B 2-\mathrm{NiAl}$ formation.

Figure. 6a presents the evolution of $B 2-\mathrm{NiAl}$ in the different systems from $10 \%$ to $60 \%$. The inflexion point corresponds to a characteristic time associated with ignition. Higher Ni concentrations in the mixing layer lead to a shift in the start of nucleation. In addition, the final amount of $B 2-\mathrm{NiAl}$ is larger in higher concentrations. This observation holds until $50 \%$. For concentrations of $\mathrm{Ni}$ equal to $60 \%$ and higher, the $f c c$ solid solution forms more rapidly at the interface and slows down the formation of $\mathrm{B} 2-\mathrm{NiAl}$.

The $\mathrm{Al}$ cohesive energy/atom $E_{0}(\mathrm{Al})$ depends on the structure to which it belongs: 


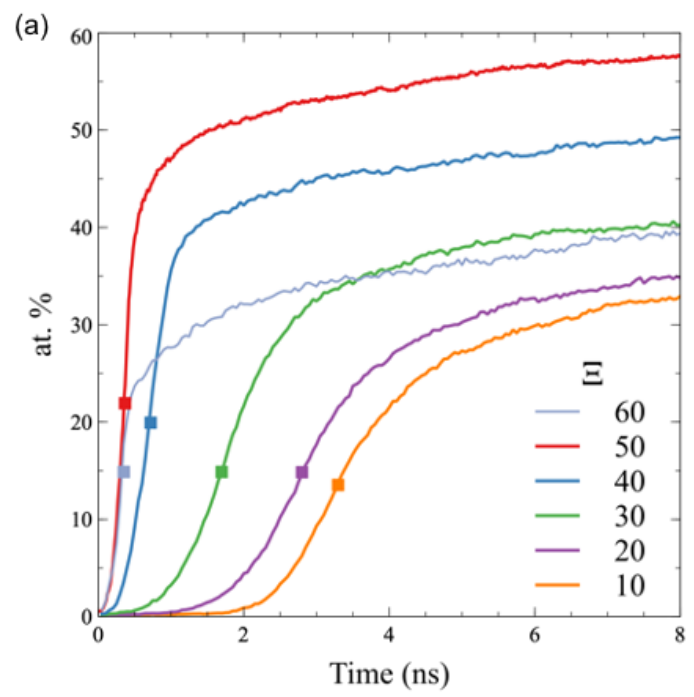

(b)

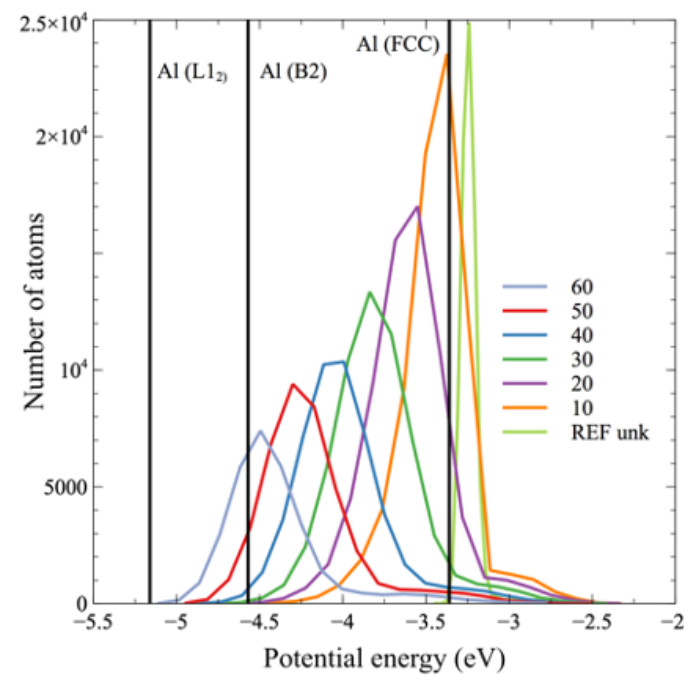

FIG. 6. (a) Evolution of at.\% of formed $B 2-\mathrm{NiAl}$ at various Ni concentrations in the mixing layer. (b) Evolution of the initial potential energy of the $\mathrm{Al}$ atoms at various Ni concentrations in the mixing layer. The three black vertical lines correspond to the potential energies of the reference structures.

$E_{0}(f c c-\mathrm{Al})=-3.36 \mathrm{eV}$ for pure $\mathrm{Al}$ and $E_{0}(b c c-\mathrm{Al})=-4.51 \mathrm{eV}$ (see Table I) for $\mathrm{Al}$ in $B 2-\mathrm{NiAl}$. Before mixing, the cohesive energy $E_{0}(u n k-\mathrm{Al})$ of amorphous $\mathrm{Al}$ atoms in the mixing layer was computed and its distribution plotted in Fig.6b (REF unk in the figure). This value is not significantly different from the value for $f c c$-atoms but we note a slight shift to the right. After random substitution of $\mathrm{Al}$ atoms by $\mathrm{Ni}$ atoms, the potential energy/atom was computed for the different substitution rates (from 10\% to $60 \%$ ). The corresponding distributions are plotted in Fig. 6b. There is an almost linear shift in the potential energy of $\mathrm{Al}$ atoms as substitution ratios increase. The potential energy/atom moves closer and closer to the reference $B 2$ value. The change in $E_{0}(\mathrm{Al})$ from the initial structure to the final structure is equal to $-0.57 \mathrm{eV}$ in the REF case (from $f c c$-Al to $B 2-\mathrm{NiAl}$ ). It reaches $-0.24 \mathrm{eV}$ in the $\mathrm{ML} 50 \%$ system (from unk-Al to B2$\mathrm{NiAl}$ ), i.e. a $42 \%$ decrease. Note that the potential energy of $\mathrm{Al}$ atoms does not evolve significantly with temperature. For instance, Fig. $6 \mathrm{~b}$ is nearly identical at $1200 \mathrm{~K}$ and 
at $900 \mathrm{~K}$. This change in $E_{0}(\mathrm{Al})$ facilitates the phase transformation in B2-NiAl. But the decrease in $E_{0}(\mathrm{Al})$ is certainly not the only factor responsible for the high reactivity observed in premixed systems. As evidence of this, the ML60\% system does not form more $B 2$ than the others.

As stated above, the purpose of this work was to evaluate the formation of $B 2-\mathrm{NiAl}$ at low temperatures to mimic the ignition of milled $\mathrm{Ni}-\mathrm{Al}$ which usually occurs experimentally at around $750 \mathrm{~K}^{6}$. The temperatures chosen for our simulations are higher in order to obtain results within an acceptable computing time.

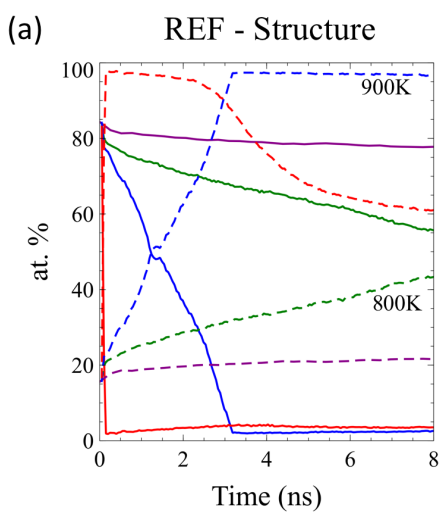

- $1200 \mathrm{~K}$ (b)

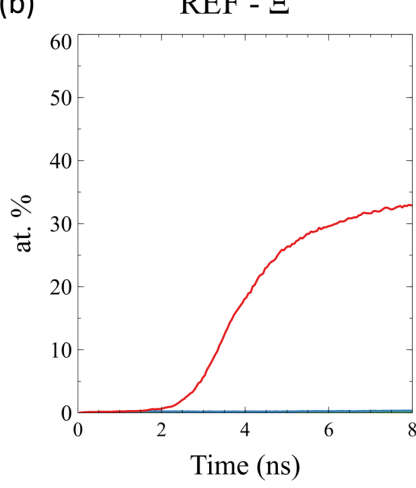

$900 \mathrm{~K}$

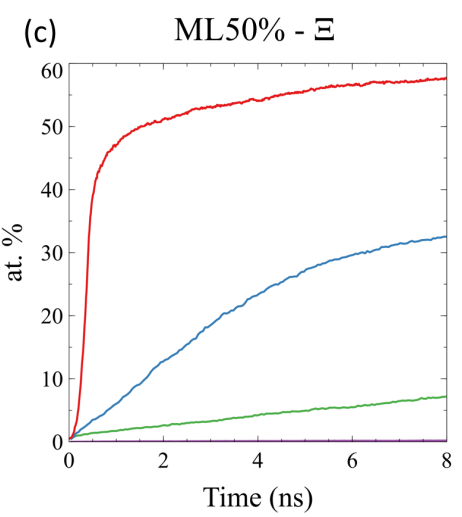

$800 \mathrm{~K}$

$600 \mathrm{~K}$

FIG. 7. (a) Evolution of the $\%$ of $f c c-\mathrm{Al}$ atoms (solid lines) and amorphous $\mathrm{Al}$ atoms (dashed lines) in the REF system at different temperatures. Evolution of the at.\% of formed $B 2-\mathrm{NiAl}$ as a function of time at different temperatures. : (b) REF system (c) ML50\%.

First, the actual Al melting temperature in the particular geometry was roughly estimated. Figure. 7a gives the number of $u n k-\mathrm{Al}$ as a function of time in the reference system at different temperatures. At $800 \mathrm{~K}$, most Al-atoms remain $f c c$. At $900 \mathrm{~K}$, after $4 \mathrm{~ns}$, all the aluminum has melted. In this geometry, the effective Al melting temperature seems to be in the range of $[800 \mathrm{~K}-900 \mathrm{~K}]$, much lower than the bulk melting temperature of $1055 \mathrm{~K}$ (see Table I). However, simply meeting the criterion of a melted 
inner layer is not enough to ensure the formation of $B 2-\mathrm{NiAl}$. Indeed, the REF systems at $900 \mathrm{~K}$ up to $1100 \mathrm{~K}$ do not exhibit the formation of $B 2-\mathrm{NiAl}$ (see Fig. 7b).

The evolution of the $\Xi$ factor is plotted in Fig. $7 \mathrm{c}$ at different operating temperatures in the case of ML50\%. In this pre-mixed system, B2-NiAl is formed even at $800 \mathrm{~K}$, below the effective melting temperature. The $(\mathrm{Al}+\mathrm{Ni})_{\text {solid }}$ is in an amorphous or supercooled state. Hence, for a high Ni concentration in the mixing layer, this configuration already exhibits solid state reaction at $800 \mathrm{~K}$. Formation of $\mathrm{B} 2-\mathrm{NiAl}$ becomes more significant at $900 \mathrm{~K}$.

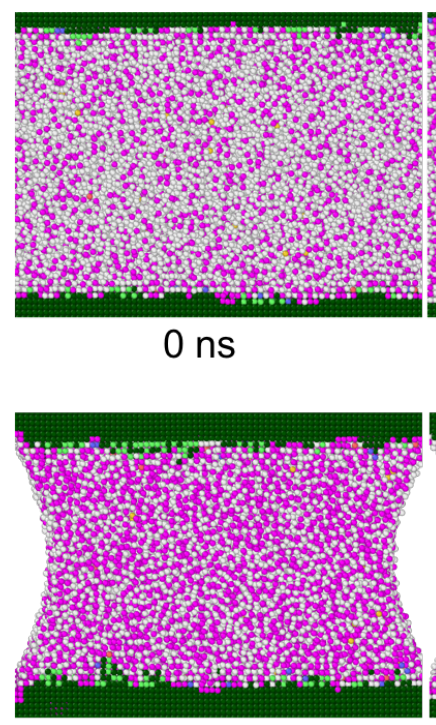

0 ns

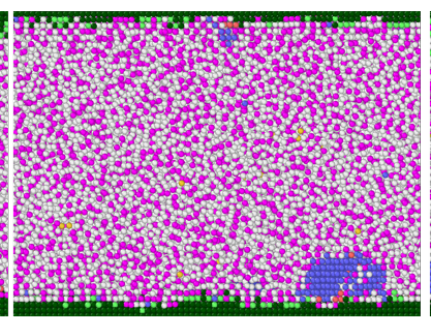

2 ns

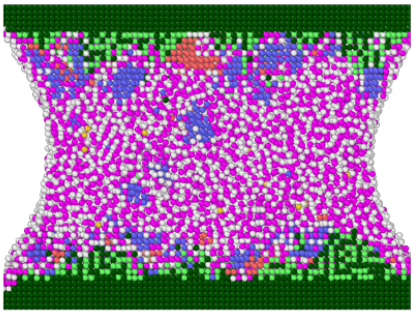

$2 \mathrm{~ns}$

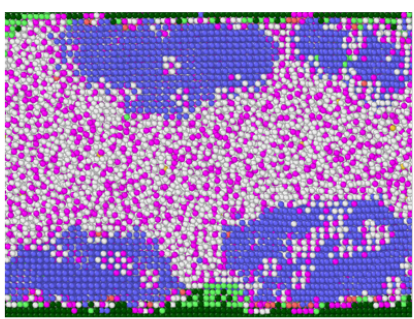

4 ns

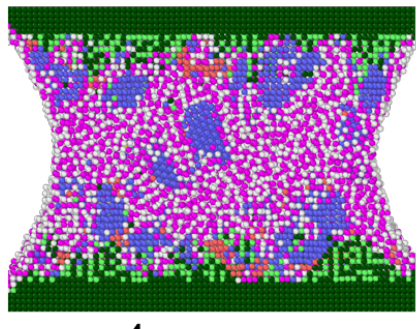

ML50\%

$900 \mathrm{~K}$

FIG. 8. Pictures of ML20 at 1200K (top) and ML50 at 900K (bottom).

It is important to compare the mechanism of $B 2-\mathrm{NiAl}$ formation at low (800 $\mathrm{K}$ and $900 \mathrm{~K})$ and high temperatures $(1200 \mathrm{~K})$ at the different rates of premixing from $20 \%$ up to $50 \%$. Figure. 8 shows representative snapshots of the ML20\% and ML50\% systems at different times during B2-NiAl formation. In ML20\%, the seeds nucleate at the interface. The nuclei grow due to precipitation of the $\mathrm{Ni}$ and $\mathrm{Al}$ atoms present in the inner layer. In the very beginning, some grains may coalesce while others grow, retaining their initial orientation. For an interface oriented normal to the [001] direc- 
TABLE III. Data on the $f c c$ solid solution formed in different simulations.

\begin{tabular}{ccccc}
\hline \hline System & ML50\% 900K & ML50\% 1200K & ML60\% 1200K & $L_{2}-\mathrm{Ni}_{3} \mathrm{Al}$ \\
\hline Al potential energy (eV) & -4.43 & -4.57 & -4.62 & -5.16 \\
\hline Ni at. \% & $50 \%$ & $55 \%$ & $62 \%$ & $75 \%$ \\
\hline \hline
\end{tabular}

tion, the intermetallic $B 2-\mathrm{NiAl}$ phase appears plane by plane. The atomic arrangement is characteristic of the (110) orientation in NiAl. In each plane, only four orientations in (110) planes were observed, due to the specific orientation relationships between $b c c$ and $f c c$-phases ${ }^{29}$. Thus, small disoriented grains separated by grain boundaries were observed. The situation is radically different in the ML50\% system at $900 \mathrm{~K}$ and $800 \mathrm{~K}$. Seeds appear in the middle of the layer, far from interfaces. This is the signature of a homogeneous nucleation. In addition, the typical profile depicted in Fig. 8 shows that the inner layer remains compact and concave in a solid amorphous state. Wetting of the Ni substrate is observed, but its impact remains limited since the layer is already amorphous. This means that the homogeneous nucleation occurs as a solid reaction. The behavior is similar at $800 \mathrm{~K}$ and $900 \mathrm{~K}$, except for the fact that $B 2$ is formed more rapidly at $900 \mathrm{~K}$. These findings indicate the possibility of $\mathrm{B} 2-\mathrm{NiAl}$ formation at temperatures below the melting point of aluminum and could explain the enhanced reactivity of milled systems.

Experimentally, the intermetallic $L 1_{2}-\mathrm{Ni}_{3} \mathrm{Al}$ phase is sometimes observed in this kind of study. In our simulation work, it does not seem to be the case. Fig. 9 shows the atoms in the $f c c$ configuration according to adaptative-CNA and the local chemical order according to the Polyhedral Template Matching ${ }^{38}$ at 8 ns. It depicts the state of the $f c c$ solid solution. Table III displays the potential energy of $\mathrm{Al}$ atoms in this configuration as well as the Ni concentration in this phase. These two elements of data point to the conclusion that the intermetallic $L 1_{0}-\mathrm{NiAl}$ or $L 1_{2}-\mathrm{Ni}_{3} \mathrm{Al}$ phases are not yet fully formed but that its formation seems underway. Indeed, in contrast to what have been reported by Turlo et al. for the Fe-Ni system ${ }^{39}$, the amount of ordered $f c c$ phase 


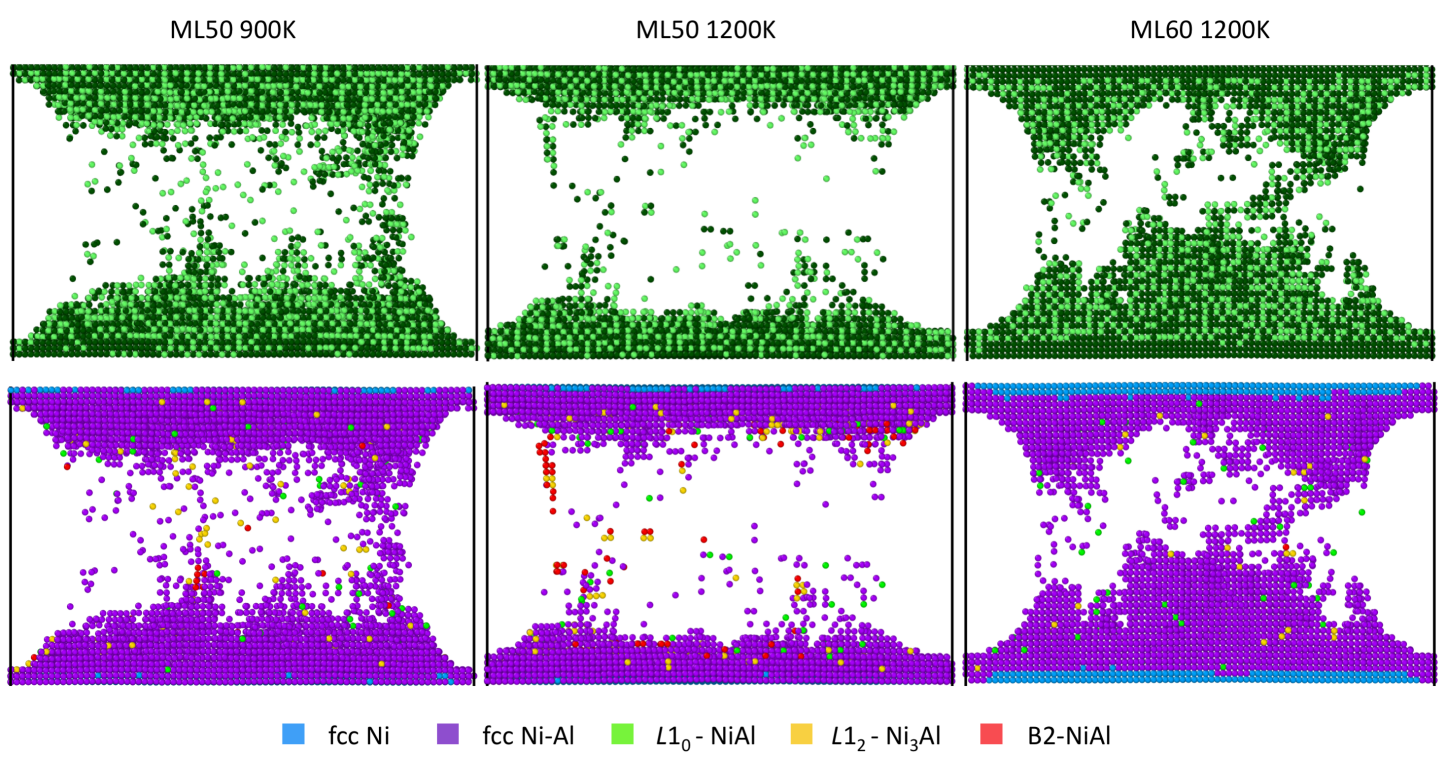

FIG. 9. Snapshots of the atoms in the $f c c$ configuration in the inner layer for ML50\% at 900K and 1200K and ML60\% 1200K. Snapshots correspond to the sate of the system at 8 ns. (Top) Dark green atoms are $f c c-\mathrm{Ni}$ atoms and light green atoms are $f c c-\mathrm{Al}$ atoms calculated with adaptative-CNA. (Bottom) Local chemical order calculated with Polyhedral Template Matching.

does not exceed $0.2 \%$ in our systems. The relative short simulation time ( $8 \mathrm{~ns}$ ) could explain why only a disordered $f c c$ solid solution could form. The lattice parameter of this solid solution is relatively close to that of pure $f c c-\mathrm{Ni}$; we may therefore assume that the solid solution plays the same role as pure $\mathrm{Ni}$ with respect to $\mathrm{B} 2-\mathrm{NiAl}$ heterogeneous nucleation.

The observation of homogeneous nucleation in a mixing layer at $900 \mathrm{~K}$ leads to other questions. Is homogeneous nucleation caused solely by the $50 \%$ pre-mixed layer? Would another premixing stoichiometry also lead to homogeneous nucleation? These questions are of great interest since an experimental milled system could be modelized as the sum of several zones, each with a different stoichiometry. Three compositions prone to homogeneous nucleation at $900 \mathrm{~K}$ were more closely studied: ML30\%, ML40\% and ML50\%. 
(a)

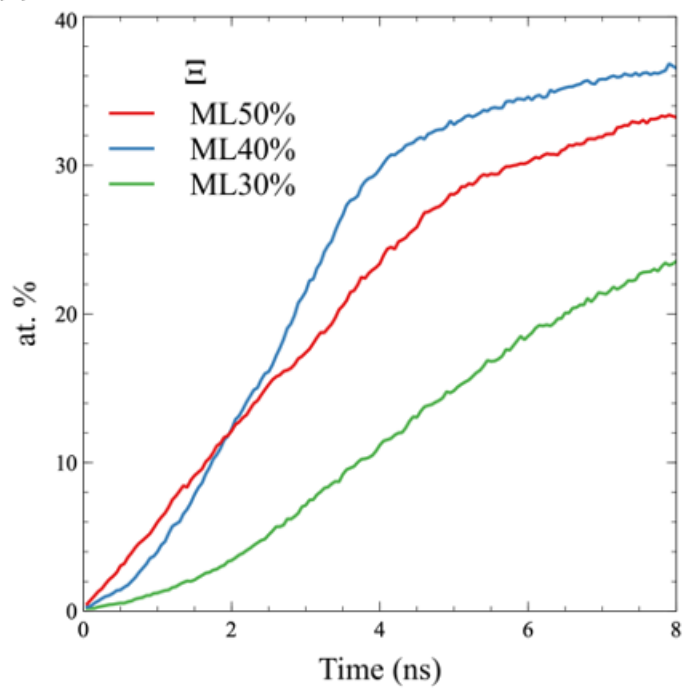

(b)

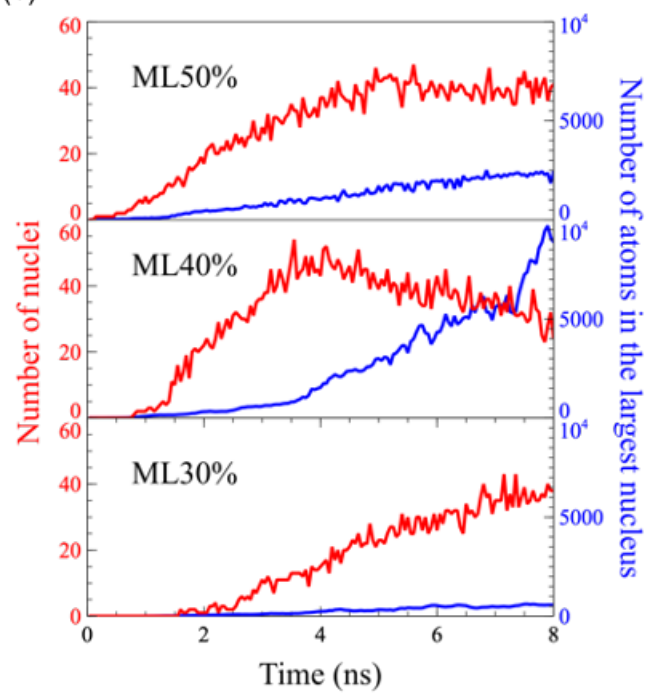

FIG. 10. (a) Evolution of the at.\% of $B 2-\mathrm{NiAl}$ at low temperature (900 K). (b) Evolution of the number of $B 2$ nuclei (red) and size of the biggest nucleus (number of atoms) (blue) over time.

Figure. 10a shows the evolution of $\Xi$ as a function of time in the three systems. We noted an unexpected finding: the formation of B2 in the case of the ML40\% system is faster and more plentiful than in the two other cases. Figure. 10b, in which we note a high nucleation rate, confirms this observation. Grain size then increases due to coalescence and precipitation. This behavior is quite similar to that observed in the $1200 \mathrm{~K}$ cases.

ML50\% at 900K exhibits a different behavior. This system shows a slower but steady nucleation rate. Grain size does not increase much, as revealed in the global evolution. At the end, there are approximately 40 nuclei and the largest grain does not exceed the size of 2000 atoms $(r=1.8 \mathrm{~nm})$.

In order to investigate the differences between behavior in ML50\% and ML40\%, representative grains in each system were followed over the course of their formation. For selected systems, a significant time was chosen. This time corresponds to the complete formation of nuclei of reasonable size. From that time, all the $\mathrm{BCC}$ atoms in a 
selected nucleus are then selected. This observation is represented in Fig. 11. The nuclei are labeled 'HON' if they form by homogeneous nucleation and 'HEN' if formed by heterogeneous nucleation. The data presented in Fig. 11 result from the tracking of several nuclei. The mean square displacement of selected atoms as a function of time is reported in Fig. 11a. No difference was noted between $\mathrm{Ni}$ and $\mathrm{Al}$ atoms. Two types of behavior were observed: (1) A strong and linear increase until 1.5ns followed by a plateau. This behavior is shared by HON40 and HEN30 grains. It reflects high mobility in the system. (2) A slight increase corresponding to very low mobility. This kind of evolution is shared by HEN40 and HON50. The ML40\% system was thus found to present both mechanisms of nucleation. Although mobility is hindered close to the interface, this is precisely where heterogeneous nucleation takes place. When mobility is high far from the interface, homogeneous nucleation develops spontaneously. Figure. $11 \mathrm{~b}$ illustrates the rearrangement of atoms during homogeneous nucleation in HON40: randomly distributed atoms diffuse and explore a large domain for $1.5 \mathrm{~ns}$ before the rapid crystallization of the $B 2-\mathrm{NiAl}$ phase. The situation is radically different in HON50, as shown in Figure. 11c. From the start, a fifth of the atoms form a seed of $b c c$-atoms that barely evolves up to $1.2 \mathrm{~ns}$. At that time, some new atoms adhere to the seed and then the rest of atoms abruptly become $b c c$. Crystallization begins sooner in the ML50\% system, but since mobility is hindered, the atoms truly rearrange into a crystalline structure only after 1 ns.

Fig. 12 depicts the evolution of the diffusion coefficient of $\mathrm{Ni}$ at $900 \mathrm{~K}$ according to concentration. The maximum is reached at around $30 \%$ and the diffusion at $40 \%$ is 1.3 times higher than at $50 \%$, according to these calculations. There are indeed different mechanisms at work in the ML40\% and ML50\% systems. The higher mobility in ML40\% is due to the lower Ni concentration. The high reactivity of activated systems results from a compromise between diffusion and previously effected mixing. 


\section{CONCLUSIONS}

The bilayer configuration with a pre-mixed zone is indeed characterized by high reactivity. Here, reactivity was evaluated by measuring the amount of $B 2-\mathrm{NiAl}$ formed during homogeneous heating. In this pre-mixed configuration, two steps usually performed over time by temperature effect are already achieved in the initial configuration. The melting and amorphization of $\mathrm{Al}$ and the diffusion of $\mathrm{Ni}$ are already accomplished. Conversely, diffusion is slower because of the pre-mixing. Taking into account the two conflicting phenomena, we nonetheless note that the pre-mixed configuration results in higher reactivity compared to the reference bilayer configuration. At the microscopic scale, it has been observed that pre-mixing decreases the cohesive energy / atom by as much as $40 \%$ for the pre-mixing with $50 \%$ Nickel.

At low temperatures below the melting temperature of $\mathrm{Al}$, homogeneous and heterogeneous nucleation occur in concentrated pre-mixing zones. The presence of both kinds of nucleation leads to faster formation of higher amounts of B2-NiAl, whereas in systems where only heterogeneous nucleation occurs, the formation is slower. It is interesting to note that the equimolar stoichiometry $50 \% \mathrm{Al}-50 \% \mathrm{Ni}$ is not associated with the best reactivity at low temperature. The mobility of atoms indeed seems to be the predominant factor in the onset of reaction. A slightly less concentrated system (ML40\%) is a better compromise to ensure higher reactivity.

In addition, in cases in which the system is not pre-mixed, the $\mathrm{Ni} / \mathrm{Al}$ interfaces are rapidly saturated and the formation of $B 2$ slows down the interdiffusion of $\mathrm{Ni}$. The intermetallics formed at the interfaces seem to channel the Ni diffusion through grain boundaries. Thus, the formation at the center of the inner layer is possible but inhibited.

In conclusion, our simulations demonstrate that the nano-scale mixing of the reagents (factor (vi) as suggested by Rogachev et al.) is indeed an activating factor. Experimentally, the two main conclusions drawn in this work could still stand. At low temperature, pre-mixing does not seem to slow down the diffusion of the Ni atoms in an amorphous $\mathrm{Al}$ region. In addition, the homogeneous nucleation resulting from the peculiar milled 
microstructure would accelerate the general reaction of $\mathrm{B} 2-\mathrm{NiAl}$ formation. Interestingly enough, similar results were obtained in the case of irradiated films where a Ni/Al amorphous interlayer was generated and found to be improving the general reaction 40

There remain several parameters which could be added to the simulation to better mimic the milled system. In addition to the nano-scale mixing (vi), the role of defects created by plastic deformation (ii) could be investigated. Point defects and grain boundaries might enhance the general diffusivity of the system, whereas dislocations could act as nucleation sites ${ }^{41}$. Nanoscale porosity could also change the process dynamics and nucleation features ${ }^{17}$. The combined consequences of all these aspects milling need, however, to be thoroughly studied.

\section{ACKNOWLEDGMENTS}

The use of computational facilities at the Computing Center of the University of Bourgogne, PSIUN-CCUB, is gratefully acknowledged.

\section{DATA AVAILABILITY}

The data that support the findings of this study are available from the corresponding author upon reasonable request.

\section{REFERENCES}

${ }^{1}$ J.S. Benjamin, Metall. Trans. 1, 2943-2951 (1970)

${ }^{2}$ C. Suryanarayana, Prog. Mater. Sci. 46, 1-184 (2001)

${ }^{3}$ E. Gaffet, F. Bernard, Int. J. SHS 10, 109-132 (2001)

${ }^{4}$ F. Maglia, U. Anselmi-Tamburini, C. Deidda, F. Delogu, G. Cocco, Z.A. Munir, J. Mater. Sci. 39, 5227-5230 (2004) 
${ }^{5}$ J.D.E. White, R.V. Reeves, S.F. Son, A.S. Mukasyan, J. Phys. Chem. A 113, 1354113547 (2009)

${ }^{6}$ A.S. Rogachev, N.F. Shkodich, S.G. Vadchenko, F. Baras, D.Yu. Kovalev, S. Rouvimov, A.A. Nepapushev, A.S. Mukasyan, J. Alloys Compd. 577, 600-605 (2013)

${ }^{7}$ A.S. Rogachev, D.O. Moskovskikh, A.A. Nepapushev, T.A. Sviridova, S.G. Vadchenko, S.A. Rogachev, A.S. Mukasyan, Powder Technol. 274, 44-52 (2015)

${ }^{8}$ F. Delogu, G. Cocco, Phys. Rev. B 71, 144108 (2005)

${ }^{9}$ H.-J. Kim, S. Karthikeyan, D. Rigney, Wear 267, 1130-1136 (2009)

${ }^{10}$ B. Li, P.C. Clapp, J.A. Rifkin, X.M. Zhang, Int. J. Heat Mass Transf. 46, 37-43 (2003)

${ }^{11}$ K. Chen, L. Wang, Y. Chen, Q. Wang, Numer. Heat Transf. Part Appl. 72, 519-535 (2017)

${ }^{12}$ K. Chen, L. Wang, Y. Chen, Q. Wang, Int. J. Heat Mass Transf. 109, 293-301 (2017)

${ }^{13}$ S. Odunuga, Y. Li, P. Krasnochtchekov, P. Bellon, R.S. Averback, Phys. Rev. Lett. 95, 045901 (2005)

${ }^{14}$ F. Delogu, J. Appl. Phys. 104, 073533 (2008)

${ }^{15}$ M.J. Cherukara, T.C. Germann, E.M. Kober, A. Strachan, J. Phys. Chem. C 120, 6804-6813 (2016)

${ }^{16}$ M.J. Cherukara, T.C. Germann, E.M. Kober, A. Strachan, J. Phys. Chem. C 118, 26377-26386 (2014)

${ }^{17}$ K.V. Manukyan, B.A. Mason, L.J. Groven, Y.C. Lin, M.J. Cherukara, S.F. Son, A. Strachan, A.S. Mukasyan, J. Phys. Chem. C 116, 21027-21038 (2012)

${ }^{18}$ Y. Xiong, S. Xiao, H. Deng, W. Zhu, W. Hu, Phys. Chem. Chem. Phys. 19, 1760717617 (2017)

${ }^{19}$ B. Witbeck, J. Sink, D.E. Spearot, J. Appl. Phys. 124, 045105 (2018)

${ }^{20}$ B. Witbeck, D.E. Spearot, J. Mater. Res. 34, 2229-2238 (2019)

${ }^{21}$ J.C. Crone, J. Knap, P.W. Chung, B.M. Rice, Appl. Phys. Lett. 98, 141910 (2011)

${ }^{22}$ M.J. Cherukara, K.G. Vishnu, A. Strachan, Phys. Rev. B 86, 075470 (2012) 
${ }^{23}$ A.J. Gavens, D. Van Heerden, A.B. Mann, M.E. Reiss, T.P. Weihs, J. Appl. Phys. 87, 1255-1263 (2000)

${ }^{24}$ M.L. Falk, T.P. Weihs, J. Chem. Phys. 146, 184501 (2017)

${ }^{25}$ P. Yi, M.L. Falk, T.P. Weihs, J. Appl. Phys. 124, 165303 (2018)

${ }^{26}$ P. Kuhn, J. Horbach, Phys. Rev. B 87, 014105 (2013)

${ }^{27}$ A. Ovrutsky, A. Prokhoda, Comput. Mater. Sci. 79, 193-200 (2013)

${ }^{28}$ F. Baras, O. Politano, Phys. Rev B 84, 024113 (2011)

${ }^{29}$ F. Baras, O. Politano, Acta Mater. 148, 133-146 (2018)

${ }^{30}$ A.S. Rogachev, Russian Chemical Review 88, 875-900 (2019)

${ }^{31}$ G.P.Purja Pun, Y. Mishin, Philos. Mag. 89, 3245-3267 (2009)

${ }^{32}$ V.Turlo, F. Baras and O. Politano, Modelling Simul. Mater. Sci. Eng. 25, 064002 (2017).

${ }^{33}$ see http://lammps.sandia.gov/; S. Plimpton, "Fast parallel algorithms for short-range molecular dynamics", J. Comp. Phys. 117, (1995)

${ }^{34}$ A. Stukowski, Model. Simul. Mater. Sci. Eng. 18, 015012 (2010)

${ }^{35}$ A.S. Rogachev, S.G. Vadchenko, F. Baras, O. Politano, S. Rouvimov, N.V. Sachkova, M.D. Grapes, T.P. Weihs, A.S. Mukasyan, Comb. Flame 166, 158-169 (2016).

${ }^{36}$ K.V. Manukyan, C.E. Shuck, M.J. Cherukara, S. Rouvimov, D.Y. Kovalev, A. Strachan, A.S. Mukasyan, J. Phys. Chem. 120, $5827-5838$ (2016)

${ }^{37}$ V. Turlo, O. Politano, F. Baras, Acta Mater. 99, 363-372 (2015).

${ }^{38}$ P.M. Larsen, S. Schmidt, J. Shiøtz, Modelling Simul. Mater. Sci. Eng. 24, 055007 (2016)

${ }^{39}$ V. Turlo, T.J. Rupert, Phys. Rev. Lett. 122, 126102 (2019)

${ }^{40}$ K.V. Manukyan, W. Tan, R.J. deBoer, E.J. Stech, A. Aprahamian, M. Wiescher, S. Rouvimov, K.R. Overdeep, C.E. Shuck, T.P. Weihs, A.S. Mukasyan, ACS Appl. Mater. Interfaces 7, 11272-11279 (2015)

${ }^{41}$ V. Turlo, T.J. Rupert, Acta Mater. 151, 100-111 (2018). 
(a)

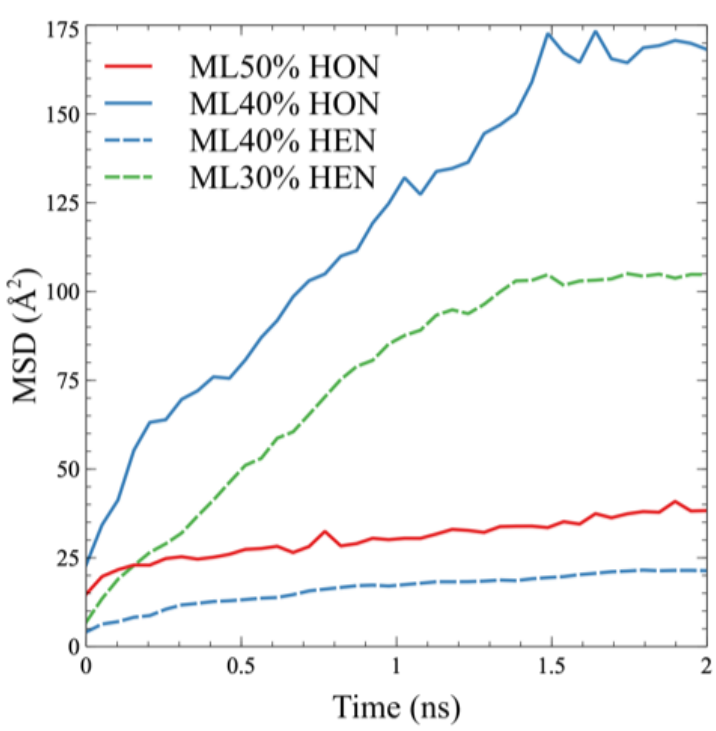

(c)

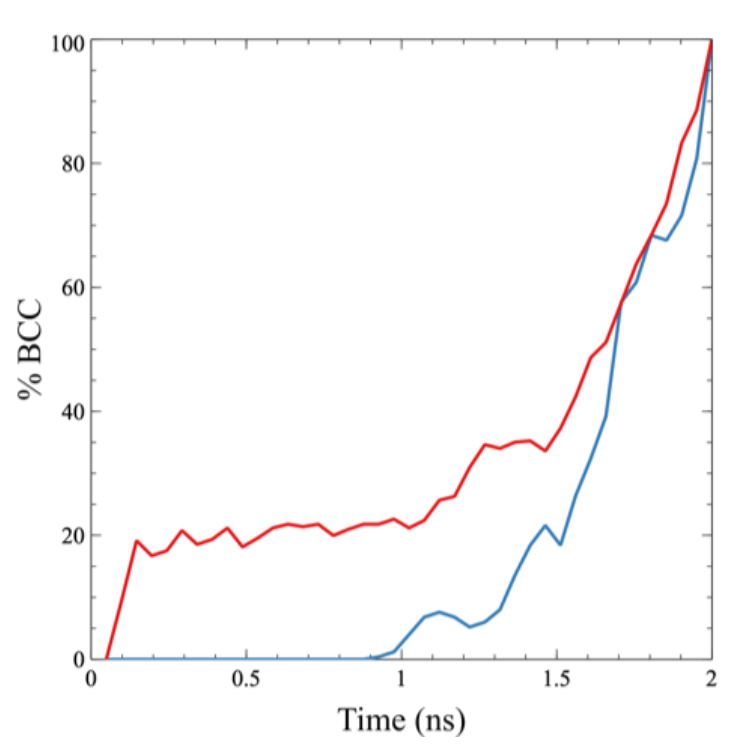

(b)

ML40\% HON

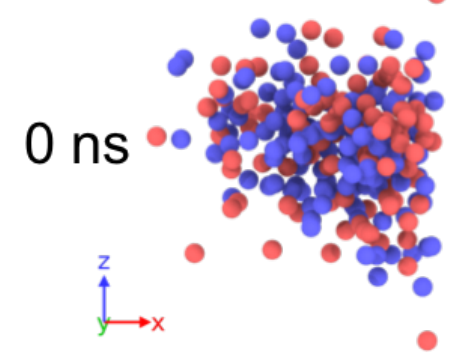

2 ns

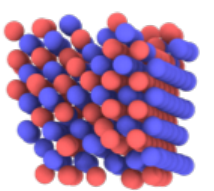

FIG. 11. Analysis of the homogeneous (HON) and heterogeneous (HEN) nuclei in ML30\%, ML40\% and ML50\%. (a) Evolution of the MSD in different groups of selected atoms. (b) Snapshots of a HON 40 at the beginning (amorphous state) and at the end of the observation (fully crystallized in the $B 2$ configuration). (c) Evolution of the percentage of BCC amongst the selected atoms. 


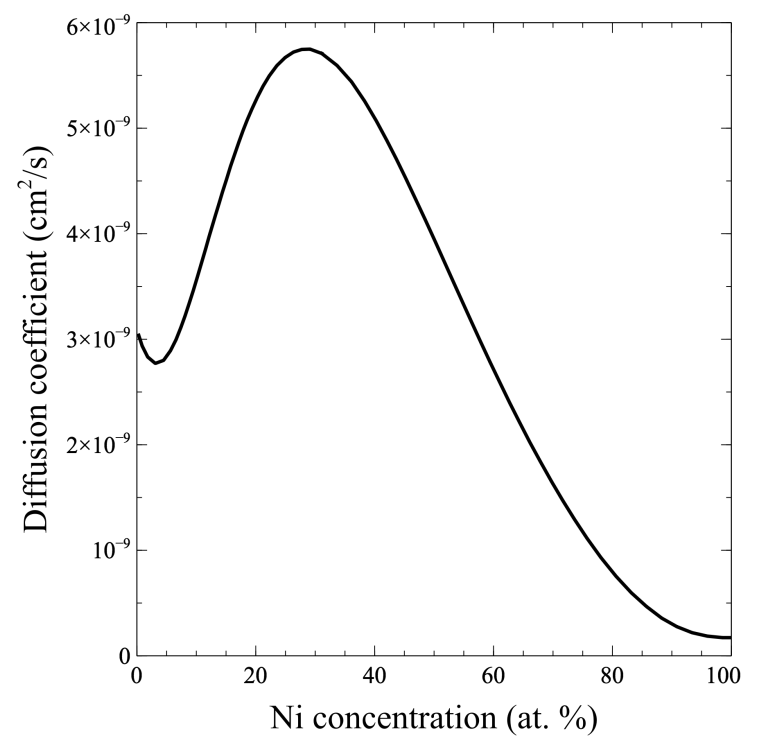

FIG. 12. Evolution of the diffusion coefficient of $\mathrm{Ni}$ in amorphous $\mathrm{Al}$ at $900 \mathrm{~K}$ according to $\mathrm{Ni}$ concentration. Calculated with ThermoCalc and Dictra using the MOBHEA1 database. 